\title{
Bidirectional Associations Between Sibling Relationships and Parental Support During Adolescence
}

\author{
Marleen M. S. Derkman • Rutger C. M. E. Engels • \\ Emmanuel Kuntsche $\cdot$ Haske van der Vorst • \\ Ron H. J. Scholte
}

Received: 8 April 2010/Accepted: 17 July 2010/Published online: 30 July 2010

(C) The Author(s) 2010. This article is published with open access at Springerlink.com

\begin{abstract}
Sibling relationships and parental support are important for adolescents' development and well-being, yet both are likely to change during adolescence. Since adolescents participate in both the sibling relationship and the parent-child relationship, we can expect sibling relationships and parental support to be associated with each other. Theoretically, it can be expected that there is either a spillover from one relationship to another (congruence hypothesis) or that one relationship can compensate for the other (compensation hypothesis). However, research examining these associations in adolescence is limited. The present study longitudinally investigated the bidirectional associations between sibling relationships and parental support during adolescence. For five consecutive years, data were collected using self-reports of 428 families, consisting of a father, a mother, and two adolescent siblings. The mean ages of the first-born (52.8\% males) and second-born ( $47.7 \%$ males) were 15 and 13 years at $\mathrm{T} 1$, respectively. For the second-born siblings, prospective associations were found between sibling relationships and adolescent-reported parental support in early adolescence, with no differences between same-sex and mixed-sex dyads. These associations were not found for first-born siblings or for parents' reports of support. The findings suggest a spillover from the sibling relationship to adolescent-reported parental support only in early adolescence.
\end{abstract}

M. M. S. Derkman $(\varangle)$ - R. C. M. E. Engels ·

H. van der Vorst . R. H. J. Scholte

Behavioural Science Institute, Radboud University Nijmegen,

PO Box 9104, 6500 HE Nijmegen, The Netherlands

e-mail: m.derkman@pwo.ru.nl

E. Kuntsche

Research Department, Swiss Institute for the Prevention

of Alcohol and Drug Problems, Lausanne, Switzerland
Findings and implications are discussed in terms of the congruence/spillover and the compensation hypothesis.

Keywords Cross-lagged models - Longitudinal · Sibling warmth and conflict $\cdot$ Parental support

\section{Introduction}

Sibling relationships and parental support are significant in the lives of children and adolescents (Blyth et al. 1982). Research shows that parental support is an important characteristic of the parent-child relationship and that sibling warmth and conflict are important characteristics of sibling relationships (Furman and Buhrmester 1985; Levitt et al. 2007). Both parental support and sibling relationship qualities are strongly related to adolescents' well-being, social development, and self-esteem (e.g., Baltes and Silverberg 1994; Garnefski and Diekstra 1996; Kim et al. 2007; Levitt et al. 1993; Yeh and Lempers 2004), and both are also likely to change during adolescence (Cole and Kerns 2001). Although a growing body of research examines sibling relationships during adolescence, little is known about the longitudinal and bidirectional associations between sibling relationships and parental support. Therefore, the aim of this study was to longitudinally examine the bidirectional associations between the quality of sibling relationships and parental support during adolescence.

\section{Sibling Relationships and Parental Support During Adolescence}

During adolescence, sibling relationships are likely to change. Although such changes might be somewhat 
different for first- and second-born siblings, the research generally reveals that the quality of the sibling relationship is high in childhood (until about age 10), declines in early adolescence (approximately age 10-15), and then increases later in adolescence (from about age 15 and older) and adulthood (e.g., Cicirelli 1995; McHale et al. 2006). In particular, early adolescents seem to experience less warmth and more conflict in their sibling relationships than children do (e.g., Brody et al. 1994a; Buhrmester and Furman 1990; Cole and Kerns 2001). Cross-sectional research shows that feelings of warmth between siblings tend to increase again as adolescents grow older and enter young adulthood (e.g., Cicirelli 1995; Scharf et al. 2005) while conflicts tend to decline in middle and late adolescence (Buhrmester and Furman 1990; Scharf et al. 2005).

Longitudinal research suggests that the patterns of changes in sibling relations may vary as a function of the sex constellation of the sibling dyad. For example, Kim et al. (2006) reported that no change in warmth occurs in same-sex dyads whereas adolescents in mixed-sex dyads experience a decline in warmth from middle childhood through early adolescence and an increase during middle adolescence. Moreover, they found that conflict declines during adolescence for both same-sex and mixed-sex dyads. As adolescents become more involved in friendships and romantic relationships, they may have less time and may have less need to invest in sibling relationships, which could explain the lower levels of sibling warmth in early adolescence. Over the course of adolescence, siblings become more involved with each other. Consequently, warmth may increase-especially in mixed-sex dyads-as these provide opportunities for advice and support about romantic relationships. At the same time, sibling relationships can be contexts for conflicts concerning autonomy and issues of individuation (Raffaelli 1992) resulting in higher levels of sibling conflict during early adolescence. During adolescence, sibling conflicts become less intense (Scharf et al. 2005) and the levels of conflict may decrease.

The level of parental support also varies over the course of adolescence. In childhood and early adolescence, parents are rated as the most frequent providers of support. In adolescence, support from best friends is often as strong as or stronger than parental support (Furman and Buhrmester 1992; Scholte et al. 2001). Yet, research has also suggested a decline in parental support during adolescence, followed by an increase or stabilization of parental support thereafter (De Goede et al. 2009; Furman and Buhrmester 1992; Helsen et al. 2000; Meeus et al. 2005). The temporary decline in parental support occurs during adolescents' increasing efforts to achieve autonomy and individuation (Meeus et al. 2005). Since adolescents desire more autonomy, they can perceive their parents as being more dominant and less supportive (De Goede et al. 2009). The decrease in perceived parental support may reflect the individuation and separation process from parents. In sum, adolescence is a period of change in which sibling relationships as well as parental support and thus parent-child relationships vary. Since adolescents are part of both of these important family relationships, we can expect these relationships to be associated with each other.

\section{Associations Between Sibling Relationships and Parental Support}

Based on the family systems theory, which proposes that families consist of interrelated subsystems that mutually influence one another (Whitchurch and Constantine 1993), it is likely that a bidirectional relationship exists between parental support and sibling relationship quality. Both the congruence hypothesis and compensation hypothesis attempt to explain the associations among various family relationships (e.g., McGuire et al. 1996; Noller 2005). The congruence hypothesis suggests a positive association or spillover between family relationships, suggesting that more positive (or negative) parent-child relationships are associated with more positive (or negative) sibling relationships. In contrast, according to the compensation hypothesis, negative relationships with some family members may be compensated by more positive relationships with other family members. According to this hypothesis, adolescents may compensate for negative parent-child relationships by establishing more positive sibling relationships.

Most research falls in line with the congruence (or spillover) hypothesis as it shows positive associations between parent-child and sibling relationships (e.g., Brody et al. 1994b; McGuire et al. 1996; McHale et al. 2006; Noller 2005; Rinaldi and Howe 2003; Seginer 1998; Stocker 2000). Different theories have been put forth to explain the processes behind this positive association among family relationships (see Brody et al. 1994b; Stocker 2000). For example, social learning theory proposes that parents function as role models through which children learn how to behave in relationships. Attachment theory suggests that children develop internal working models of relationships based on their early experiences in the parent-child relationship. These internal working models will, in turn, function as the basis to form other relationships, including the sibling relationship. Finally, it might also be that children's personality brings forth similar responses from both parents and siblings, leading to the positive association between these relationships (Brody et al. 1994b; Stocker 2000).

Although most research supports the congruence hypothesis, some cross-sectional studies show that compensation rather than congruency may occur between 
parent-child and sibling relationships (e.g., Jenkins 1992; Voorpostel and Blieszner 2008). Jenkins (1992) demonstrated that compensation between parent-child and sibling relationships only occurs in disharmonious families, not in harmonious families. More recently, Voorpostel and Blieszner (2008) found that, among adults, a positive relationship with one parent can compensate for a negative relationship with a sibling and vice versa. Thus, compensation might be more common in disharmonious families or in adulthood. However, it is important to note that the majority of these studies are either cross-sectional or focused on associations between family relationships in childhood or adulthood, but not in adolescence. One exception is a study by Kim et al. (2006), which investigated longitudinal associations between parent-child and sibling relationships throughout adolescence. They found that increases in positive mother-child relationships were linked to increases in positive sibling relationships while increases in father-child conflict were linked to increases in sibling conflict. Our study extends previous research as it examines multiple associations between family relations, using a longitudinal bidirectional design — an approach not frequently used to date.

\section{The Current Study}

The current study investigated the longitudinal bidirectional associations between parental support on one hand and sibling warmth and conflict on the other for five consecutive years during adolescence. We expected positive bidirectional associations among family relationships; in other words, we predicted that higher levels of parental support would be associated with more warmth and less conflict in sibling relationships each subsequent year, and vice versa. Because the quality of the marital relationship, which is another important family subsystem, is related to parent-child and sibling relationships (e.g., Brody et al. 1994a, b; Kim et al. 2006; Noller 2005), we controlled for it in the current study.

We examined the associations between parental support and sibling relationship quality in a sample of second-born siblings as these siblings were at the age of entering adolescence. However, since gender constellations and birth order have to be considered when investigating sibling relationships (Buhrmester and Furman 1990; Cicirelli 1995; Cole and Kerns 2001; Kim et al. 2006), we also investigated the associations between parental support and sibling relationship quality in same- and mixed-sex sibling dyads as well as in first-born siblings.

Finally, previous studies have focused primarily on adolescents' perceptions of parental support and as such did not include parents' reports of parental support. Since parents and adolescents may differ in the perceptions of parental support (see e.g., Sarason et al. 1990), our understanding of the associations between sibling relationships and parental support may be incomplete if we rely exclusively on adolescents' self-reports (e.g., Bogenschneider and Pallock 2008). Therefore, we also investigated whether support reported by parents was associated with sibling relationships.

\section{Method}

Participants

We used data from 428 families, each consisting of a father, a mother, and two adolescent children. The mean ages of fathers and mothers at baseline were 46.2 $(\mathrm{SD}=4.00)$ and $43.8(\mathrm{SD}=3.57)$, respectively. Firstborn and second-born siblings had a mean age of 15.2 $(\mathrm{SD}=.60)$ and $13.4(\mathrm{SD}=.50)$ at baseline, respectively. Of the first-born siblings, $52.8 \%$ were boys; $47.7 \%$ of the second-born siblings were boys. The majority of both the first- and second-born siblings were of Dutch origin (98.1 and $96.3 \%$, respectively). Among the sibling pairs, 108 were boy-boy dyads, 106 were girl-girl dyads, 118 were boy-girl dyads, and 96 were girl-boy dyads. Approximately one third of the siblings pursued special or low education, one third pursued intermediate general education, and the remaining siblings pursued the highest level of secondary education available in The Netherlands (i.e., college and university preparatory education).

\section{Procedure}

We used five waves of the "Family and Health" project, which assessed different socialization processes underlying various health behaviors in adolescence (Harakeh et al. 2005; Van Der Vorst et al. 2005). Initially, participants were invited to participate in the first three waves of the study. We collected the addresses of families with at least two children aged 13-16 years from 22 municipalities in The Netherlands in order to send them an invitation letter to participate. Families who responded to the invitation letter were contacted by telephone to determine whether they met the inclusion criteria (i.e., consisted of a father and mother who were married or living together and were biologically related to their children). Families with twins or offspring with identified physical or mental disabilities were excluded from the study. In addition, we made an effort to achieve an equal distribution of adolescents' education level (one third in special or low education, one third in intermediate general education, and one third in 
college and university preparatory education) and an equal division of sibling dyads (i.e., boy-boy, girl-girl, boy-girl, girl-boy). As a result, 428 families participated. Approval for the data collection procedures was obtained from the independent medical ethics committee METiGG in Utrecht, The Netherlands (2006, no. 6209).

Baseline data collection (T1) took place between November 2002 and April 2003; the second (T2) and third wave (T3) measurements took place at successive 1-year intervals. A total of 416 families were included at T2 and 404 at T3. Interviewers visited the families at their homes and asked all four family members to complete the questionnaires individually and simultaneously. All participants gave their written informed consent, and each family received 30 euros for their participation after all family members had completed the questionnaires. After the first three waves, the families were once again invited to participate in new annual measurement waves; 356 families participated at T4, and 326 families at T5. For practical and financial reasons, some families received the questionnaires by mail at T4 and T5. Travel vouchers valued at 1,000 euros each and iPods were raffled among the families who participated in all five waves.

We conducted attrition analyses to examine whether families who participated in all five waves differed from families who did not participate in all five waves. $T$-tests showed no significant differences in sibling warmth $[t(426)=0.59, p=.55$ and $t(425)=1.57, p=0.12$ for second-born and first-born siblings, respectively], sibling conflict $[t(426)=-1.36, p=.18$ and $t(425)=-0.80$, $p=.42$ for second-born and first-born siblings, respectively], parental support $[t(425)=0.74, p=.46]$, or marital relationship quality $[t(425)=1.03, \quad p=.31]$. Compared to families who did not participate in all five waves, fathers, second-born siblings, and first-born siblings in families who participated in all five waves had slightly higher educational levels [for fathers $\chi^{2}(1)=5.70$, $p<.05$; for second-born siblings $\chi^{2}(1)=19.48, p<.001$; for first-born siblings $\left.\chi^{2}(1)=21.60, p<.001\right]$.

\section{Measures}

Sibling Relationship Quality. The siblings completed 21 items of the Sibling Relationship Questionnaire (SRQ; Furman and Buhrmester 1985) at each wave to assess warmth (15 items) and conflict (6 items) in their relationship with their sibling, who also participated in the study. The SRQ proved to be a valid and reliable instrument for assessing aspects of the sibling relationship (Derkman et al. 2010; Furman and Buhrmester 1985). Participants answered the items on a 5-point scale ranging from (1) hardly at all to (5) extremely much, assessing the extent to which certain features were characteristic of their sibling relationship. An example of a warmth item is "How much do you and this sibling do nice things for each other?" An example of a conflict item is "How much do you and this sibling disagree and quarrel with each other?" Cronbach's alphas for warmth ranged from .91 to .93 across waves for both siblings. Cronbach's alphas for conflict ranged from .83 to .87 across waves for both siblings. Higher scores on the warmth and conflict dimensions represent more warmth and conflict in the sibling relationship.

Adolescents' Reports of Parental Support. At each wave, adolescents reported their perception of the instrumental and emotional support they received from their fathers and mothers by completing 12 items of the Relational Support Inventory (RSI; Scholte et al. 2001) using a 5-point scale ranging from (1) very untrue to (5) very true. Examples of items are "My father/mother shows me that he/she loves me" and "My father/mother explains to me how I can do or make something." Cronbach's alphas ranged from .76 to .88 for perceived support from both fathers and mothers across all five waves for both secondborn and first-born siblings. Adolescents' reports of maternal and paternal support were highly correlated, with correlations ranging from $r=.58, p<.001$ to $r=.69$, $p<.001$ across waves for both siblings. Higher scores reflected more perceived parental support.

Parents' Reports of Parental Support. Both fathers and mothers responded to 12 items of the RSI (Scholte et al. 2001) to assess their perceptions of the instrumental and emotional support they provided to their children using a 5-point scale ranging from (1) very untrue to (5) very true. An example of an item is "I show my child that I love him/ her." Cronbach's alphas ranged from .79 to .85 for paternal support and from .83 to .86 for maternal support across all five waves. Maternal and paternal support were marginally correlated, with correlations ranging from $r=.21, p<$ .001 to $r=.28, p<.001$ across waves. Higher scores indicated more paternal or maternal support.

Marital Relationship Quality. To assess the quality of marital relationships, both fathers and mothers completed 15 items of the Marital Adjustment Test (MAT; Locke and Wallace 1959). The MAT is a frequently used and reliable questionnaire (e.g., Ha et al. 2009), with a reliability coefficient of .90 (e.g., Locke and Wallace 1959). Parents responded to items such as "Do you ever wish you had not married?" with the response options (1) frequently, (2) occasionally, (3) rarely, and (4) never and "If you had your life to live over, do you think you would (1) marry the same person, (2) marry a different person, or (3) not marry at all?" The possible scores ranged from 2 to 158 , with scores below 100 indicating low marital relationship quality (Crane et al. 1990). We combined fathers' and mothers' mean scores concerning their marital relationship, as the reports on marital relationships were significantly 


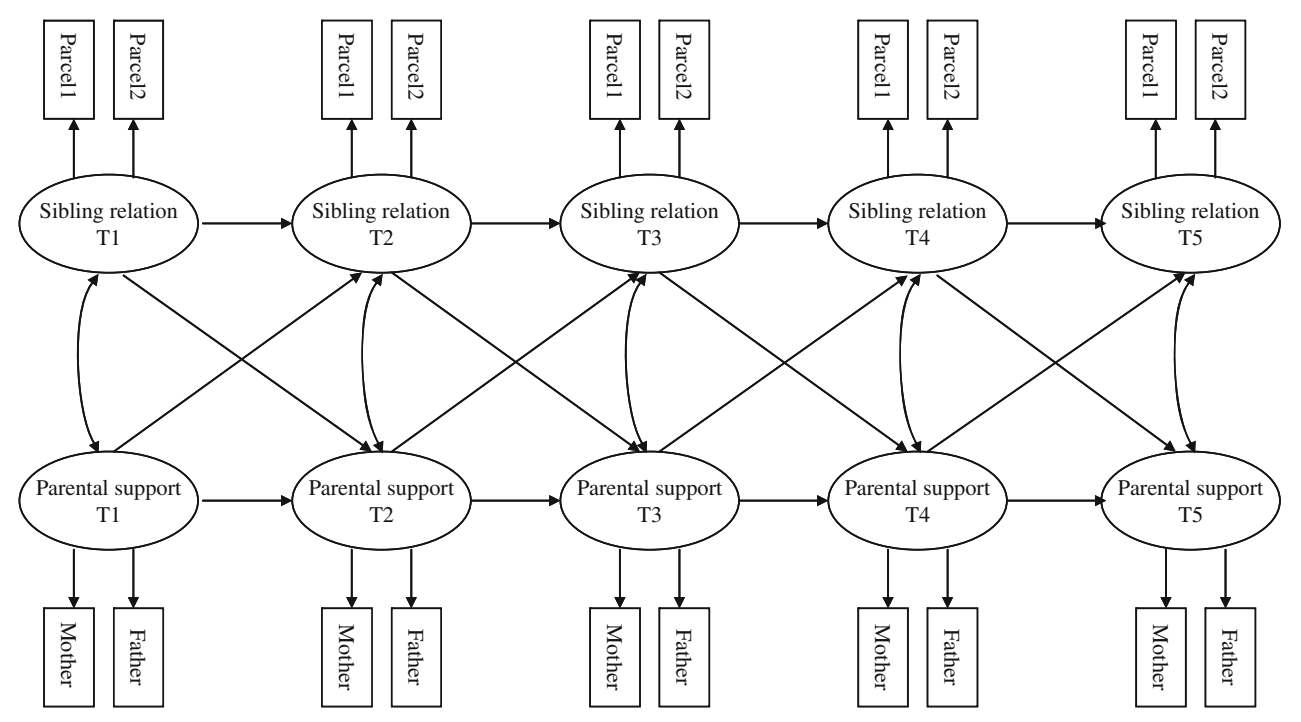

Fig. 1 Basic model concerning associations between sibling relationship quality and adolescents' reports of parental support. Note. To control for marital relationship quality, we added marital relationship

correlated (ranging from $r=.53, p<.001$ to $r=.64$, $p<.001$ across waves). Higher scores on this scale indicated a higher quality marital relationship.

\section{Strategy of Analyses}

For the descriptive part of the study, we computed means and standard deviations of the main study variables as well as Pearson correlations between these variables. To test our longitudinal cross-lagged model (see Fig. 1), in which we investigated the bidirectional associations between sibling relationships and parental support from year to year, we performed structural equation modeling (SEM) using the software package Mplus (Muthén and Muthén 1998-2007). We included adolescents' reports of parental support, sibling warmth, and sibling conflict assessed at each wave (T1 to T5) as latent variables in the model. Two parcels assessed each latent warmth and conflict variable (e.g., Bandalos and Finney 2001; Nasser and Takahashi 2003), with each parcel representing half of the scale items (see e.g., De Leeuw et al. 2008). Two parcels also assessed the latent parental support variables. The first parcel represented adolescents' reports of maternal support (12 items) while the second parcel represented adolescents' reports of paternal support (12 items). The error terms of the corresponding parcels were allowed to correlate across two subsequent waves since they were believed to be stable and to correlate highly across assessment waves. Furthermore, we controlled for marital relationship quality by adding this measurement at $\mathrm{T} 1$ as a predictor for the model, allowing this variable to correlate with parental support, sibling warmth, and sibling conflict at each wave (T1 to T5). To quality at $\mathrm{T} 1$ as a predictor to the model and allowed this variable to correlate with parental support, sibling warmth, and sibling conflict at $\mathrm{T} 1$ to $\mathrm{T} 5$

make optimal use of all available data points, we let Mplus handle the missing data using the Full-Information Maximum Likelihood option (FIML; Muthén and Muthén 19982007). FIML enables Mplus to make use of all available data points, even for cases with some missing responses.

We first tested the cross-lagged model of sibling warmth and adolescents' reports of parental support in the total sample of second-born siblings; we then did the same for sibling conflict. Due to limited statistical power, we were not able to test the models for all four gender constellation dyads (i.e., boy-boy, girl-girl, boy-girl, and girl-boy). Rather, we tested the models for same-sex (girl-girl and boy-boy dyads) versus mixed-sex dyads (boy-girl and girl-boy dyads) by performing multi-group analyses. We tested whether the model fit was significantly better for the model in which the paths were allowed to differ between the groups compared to the model in which the paths were constrained to be equal. In the first step, we computed a baseline $\chi^{2}$ of the model with no equality constraints between the two groups (unconstrained model). In the next step, we computed the $\chi^{2}$ of the constrained model, in which the stability and the cross-lagged paths were constrained to be equal. If $\chi^{2}$ were to increase significantly from step 1 to step 2 , these paths would be significantly different across the sibling dyads. We then retested the cross-lagged models for sibling warmth and sibling conflict in the sample of first-born siblings. Finally, we tested the cross-lagged models for sibling warmth and conflict with parental support as reported by parents instead of adolescents. Because of the discrepancy between parental and adolescent reports of parental support models we tested separate for these two reports rather than to combine them 
into one overall construct of parental support. The fit of the models was measured by $\chi^{2}$, Comparative Fit Index (CFI, with a cutoff value close to .95), and Root Mean Square Error of Approximation (RMSEA, with a cutoff value close to .06; $\mathrm{Hu}$ and Bentler 1999).

\section{Results}

\section{Descriptive Data}

As evident in Table 1, sibling warmth and adolescentreported parental support were positively correlated, whereas sibling conflict and adolescent-reported parental support were negatively correlated across most of the five waves. At each of the five waves, more warmth in sibling relationships was associated with less sibling conflict (with $r$ ranging from -.21 to $-.32, p<.01$ ). Table 2 summarizes the calculated means and standard deviations of sibling warmth, sibling conflict, adolescents' reports of maternal and paternal support, and parents' reports of maternal and paternal support at each wave (T1 to T5) for the second-born and first-born siblings, respectively. At each wave, adolescents' reports of parental support differed significantly from parents' reports of parental support $(p<.001)$. Moreover, correlations between adolescents'

Table 1 Correlations among sibling warmth, sibling conflict, and adolescents' reports of parental support across the five waves

\begin{tabular}{|c|c|c|c|c|c|c|c|c|c|c|}
\hline & 1. & 2. & 3. & 4. & 5. & 6. & 7. & 8. & 9. & 10. \\
\hline 1. Sibling T1 & & $.55^{* *}$ & $.48 * *$ & $.39 * *$ & $.33 * *$ & $-.15^{* *}$ & $-.19 * *$ & $-.20 * *$ & $-.12 *$ & $-.15^{* *}$ \\
\hline 2. Sibling T2 & $.70 * *$ & & $.62 * *$ & $.49 * *$ & $.44 * *$ & -.09 & $-.16^{* *}$ & $-.21 * *$ & $-.13 *$ & $-.13 *$ \\
\hline 3. Sibling T3 & $.62 * *$ & $.74 * *$ & & $.65 * *$ & $.62 * *$ & $-.10^{*}$ & $-.17 * *$ & $-.24 * *$ & $-.19 * *$ & $-.19 * *$ \\
\hline 4. Sibling T4 & $.50 * *$ & $.63 * *$ & $.73 * *$ & & $.68 * *$ & $-.11 *$ & $-.16^{* *}$ & $-.16^{* *}$ & $-.21 * *$ & $-.22 * *$ \\
\hline 5. Sibling T5 & $.40 * *$ & $.56^{* *}$ & $.63 * *$ & $.78 * *$ & & -.08 & $-.20 * *$ & $-.17 * *$ & $-.19 * *$ & $-.26 * *$ \\
\hline 6. Support T1 & $.36 * *$ & $.25^{* *}$ & $.24 * *$ & $.11^{*}$ & .06 & & $.68 * *$ & $.51 * *$ & $.38 * *$ & $.37 * *$ \\
\hline 7. Support T2 & $.36 * *$ & $.31 * *$ & $.27 * *$ & $.19 * *$ & $.18 * *$ & $.68 * *$ & & $.67 * *$ & $.54 * *$ & $.47 * *$ \\
\hline 8. Support T3 & $.35 * *$ & $.31 * *$ & $.34 * *$ & $.21 * *$ & $.17 * *$ & $.51 * *$ & $.67 * *$ & & $.67 * *$ & $.61^{* *}$ \\
\hline 9. Support T4 & $.29 * *$ & $.26 * *$ & $.31 * *$ & $.36 * *$ & $.27 * *$ & $.38 * *$ & $.54 * *$ & $.67 * *$ & & $.72 * *$ \\
\hline 10. Support T5 & $.31 * *$ & $.21 * *$ & $.27 * *$ & $.30 * *$ & $.35 * *$ & $.37 * *$ & $.47 * *$ & $.61 * *$ & $.72 * *$ & \\
\hline
\end{tabular}

Sibling $=$ Sibling relationship reported by the second-born sibling, Support = Adolescents' reports of parental support. Correlations are reported for sibling conflict above the diagonal and for sibling warmth below the diagonal. Correlations for first-born siblings and for parents' reports of parental support can be obtained from the first author

$* p<.05 ; * * p<.01$

Table 2 Means $(M)$ and standard deviations (SD) of sibling warmth, sibling conflict, adolescents' reports of maternal and paternal support, and parents' reports of maternal support and paternal support from T1 to T5

\begin{tabular}{|c|c|c|c|c|c|c|c|c|c|c|}
\hline & \multicolumn{2}{|l|}{$\mathrm{T} 1$} & \multicolumn{2}{|l|}{$\mathrm{T} 2$} & \multicolumn{2}{|l|}{$\mathrm{T} 3$} & \multicolumn{2}{|l|}{$\mathrm{T} 4$} & \multicolumn{2}{|l|}{$\mathrm{T} 5$} \\
\hline & $M$ & SD & $M$ & SD & $M$ & SD & $M$ & SD & $M$ & SD \\
\hline \multicolumn{11}{|l|}{ Sibling warmth } \\
\hline Second-born & 3.26 & 0.59 & 3.29 & 0.60 & 3.33 & 0.57 & 3.34 & 0.60 & 3.32 & 0.58 \\
\hline First-born & 3.22 & 0.60 & 3.24 & 0.59 & 3.27 & 0.58 & 3.30 & 0.58 & 3.30 & 0.55 \\
\hline \multicolumn{11}{|l|}{ Sibling conflict } \\
\hline Second-born & 3.06 & 0.65 & 2.94 & 0.63 & 2.79 & 0.67 & 2.64 & 0.66 & 2.47 & 0.64 \\
\hline First-born & 3.14 & 0.61 & 3.01 & 0.63 & 2.85 & 0.59 & 2.63 & 0.61 & 2.47 & 0.61 \\
\hline \multicolumn{11}{|l|}{ Maternal support } \\
\hline Second-born & 4.12 & 0.40 & 4.08 & 0.44 & 4.06 & 0.47 & 4.08 & 0.47 & 4.08 & 0.48 \\
\hline First-born & 4.12 & 0.41 & 4.09 & 0.43 & 4.07 & 0.42 & 4.13 & 0.46 & 4.13 & 0.46 \\
\hline \multicolumn{11}{|l|}{ Paternal support } \\
\hline Second-born & 3.95 & 0.48 & 3.86 & 0.51 & 3.87 & 0.54 & 3.68 & 0.44 & 3.87 & 0.52 \\
\hline First-born & 3.93 & 0.53 & 3.89 & 0.53 & 3.86 & 0.52 & 3.70 & 0.45 & 3.96 & 0.52 \\
\hline Mothers' maternal support & 4.39 & 0.39 & 4.32 & 0.39 & 4.29 & 0.41 & 4.30 & 0.40 & 4.31 & 0.40 \\
\hline Fathers' paternal support & 4.15 & 0.39 & 4.14 & 0.37 & 4.10 & 0.41 & 4.10 & 0.39 & 4.09 & 0.40 \\
\hline
\end{tabular}


reports of parental support and parents' reports of parental support were low to moderate, ranging from .23 to .34 $(p<.001) . T$-tests also indicated that second-born siblings reported more warmth at $\mathrm{T} 2$ and $\mathrm{T} 3[t(413)=2.03$, $p=.04$ and $t(400)=2.26, p=.03$, respectively] as well as less conflict at T1 and T2 $[t(426)=-2.49, p=.01$ and $t(412)=-2.04, p=.04$ ] than first-born siblings. After calculating the descriptive statistics, we used SEM to test the longitudinal and bidirectional associations between sibling warmth and conflict on the one hand and parental support on the other.

\section{Sibling Warmth and Adolescents' Reports of Parental} Support

The model for sibling warmth and adolescents' reports of parental support showed a satisfactory fit to the data $\left[\chi^{2}(141, N=428)=378.845, p=.000, \mathrm{CFI}=.962\right.$, and $\mathrm{RMSEA}=.063]$. The factor loadings of the latent warmth variables in the model were high, ranging from .88 to .94, suggesting that the parcels accurately assessed the latent variables of warmth. The factor loadings of the latent variable parental support were also high (ranging from .73 to .87), demonstrating that the indicators correctly assessed the latent variables of parental support in the model. Beta coefficients of sibling warmth and adolescent-reported parental support showed strong stability (betas ranging from .74 to .84 and .66 to .80 , respectively, $p<.001)$, indicating that warmth in sibling relationships and adolescent-reported parental support were both relatively stable over time.

As indicated in Table 3, standardized estimates for the cross-lagged paths revealed a positive association between sibling warmth at $\mathrm{T} 1$ and adolescent-reported parental support at $\mathrm{T} 2(\beta=.15, p=.002)$ as well as between sibling warmth at $\mathrm{T} 2$ and adolescent-reported parental support at T3 ( $\beta=.11, p=.020)$. The association between sibling warmth at T3 and adolescent-reported parental support at T4 was marginally significant $(\beta=.11, p=.054)$, suggesting that more warmth in the sibling relationship at $\mathrm{T} 1$, $\mathrm{T} 2$, and $\mathrm{T} 3$ is associated with more perceived support from parents at T2, T3, and T4, respectively. From T4 to T5, no associations were found between sibling warmth and adolescent-reported parental support (see Table 3).

\section{Sibling Conflict and Adolescents' Reports of Parental Support}

The model for sibling conflict and adolescents' reports of parental support showed a satisfactory fit to the data $\left[\chi^{2}(141, N=428)=316.034, p=.000, \mathrm{CFI}=.965\right.$, and RMSEA $=.054]$. The parcels accurately assessed the latent variables of conflict in the model as the factor loadings of the latent conflict variables were high (ranging
Table 3 Beta coefficients for the basic models of sibling warmth and adolescents' reports of parental support

\begin{tabular}{ccc}
\hline & $\begin{array}{l}\text { Second-born } \\
\text { siblings } \\
\beta\end{array}$ & $\begin{array}{l}\text { First-born } \\
\text { siblings } \\
\beta\end{array}$ \\
\hline Cross-lagged paths & \\
Warmth T1 $\rightarrow$ Support T2 & $.15^{* *}$ & .03 \\
Warmth T2 $\rightarrow$ Support T3 & $.11^{*}$ & -.06 \\
Warmth T3 $\rightarrow$ Support T4 & $.11^{\dagger}$ & .06 \\
Warmth T4 $\rightarrow$ Support T5 & .02 & .03 \\
Support T1 $\rightarrow$ Warmth T2 & -.01 & -.01 \\
Support T2 $\rightarrow$ Warmth T3 & .03 & -.00 \\
Support T3 $\rightarrow$ Warmth T4 & -.03 & .01 \\
Support T4 $\rightarrow$ Warmth T5 & -.03 & -.00 \\
Cross-sectional associations & & $.39 * * *$ \\
Warmth T1 $\leftrightarrow$ Support T1 & $.42^{* * *}$ & $.31 * * *$ \\
Warmth T2 $\leftrightarrow$ Support T2 & $.14 *$ & $.22 * *$ \\
Warmth T3 $\leftrightarrow$ Support T3 & $.24 * * *$ & $.38 * * *$ \\
Warmth T4 $\leftrightarrow$ Support T4 & $.38^{* * *}$ & $.28 * * *$ \\
Warmth T5 $\leftrightarrow$ Support T5 & $.43 * * *$ & \\
\hline
\end{tabular}

The correlations between $\mathrm{T} 1$ and $\mathrm{T} 2$ are correlations between latent variables. The correlations from $\mathrm{T} 2$ and above are correlations between the disturbance terms

$* p<.05 ; * * p<.01 ; * * * p<.001{ }^{\dagger} p=.054$

from .82 to .93 ). Similar to the results from the model for sibling warmth, the factor loadings of the latent variables of parental support were high (ranging from .72 to .88), indicating that the latent variables of parental support were accurately assessed. Beta coefficients of both sibling conflict and adolescent-reported parental support showed strong stability (with betas ranging from .64 to .75 and .72 to .79 , respectively, $p<.001$ ), demonstrating that sibling conflict and adolescent-reported parental support were relatively stable over time. We found a negative association between sibling conflict at $\mathrm{T} 1$ and adolescent-reported parental support at T2 $(\beta=-.09, p=.047)$ as well as a negative association between sibling conflict at T2 and adolescent-reported parental support at $\mathrm{T} 3 \quad(\beta=-.11$, $p=.012$ ). Thus, more sibling conflict at $\mathrm{T} 1$ and $\mathrm{T} 2$ is associated with less support perceived from parents at T2 and T3, respectively. No associations were found between sibling conflict and adolescent-reported parental support from T3 to T5 (see Table 4).

\section{Same-Sex Versus Mixed-Sex Sibling Dyads}

To test whether the associations between parental support and sibling warmth and conflict differed for same-sex and mixed-sex sibling dyads, the models for same-sex dyads $(n=215)$ were compared with the models for mixed-sex dyads $(n=213)$. A Chi-square difference test demonstrated 
Table 4 Beta coefficients for the basic models of sibling conflict and adolescents' reports of parental support

\begin{tabular}{rll}
\hline & $\begin{array}{l}\text { Second-born } \\
\text { siblings } \\
\beta\end{array}$ & $\begin{array}{l}\text { First-born } \\
\text { siblings } \\
\beta\end{array}$ \\
\hline Cross-lagged paths & & \\
Conflict T1 $\rightarrow$ Support T2 & $-.09^{*}$ & -.02 \\
Conflict T2 $\rightarrow$ Support T3 & $-.11^{*}$ & -.01 \\
Conflict T3 $\rightarrow$ Support T4 & -.00 & -.07 \\
Conflict T4 $\rightarrow$ Support T5 & -.07 & -.06 \\
Support T1 $\rightarrow$ Conflict T2 & .01 & .03 \\
Support T2 $\rightarrow$ Conflict T3 & -.01 & -.03 \\
Support T3 $\rightarrow$ Conflict T4 & .01 & -.06 \\
Support T4 $\rightarrow$ Conflict T5 & -.02 & .02 \\
Cross-sectional associations & & $-.25^{* * *}$ \\
Conflict T1 $\leftrightarrow$ Support T1 & $-.13^{*}$ & -.11 \\
Conflict T2 $\leftrightarrow$ Support T2 & -.09 & .05 \\
Conflict T3 $\leftrightarrow$ Support T3 & -.12 & -.04 \\
Conflict T4 $\leftrightarrow$ Support T4 & $-.24^{* *}$ & $-.36^{* * *}$ \\
Conflict T5 $\leftrightarrow$ Support T5 & $-.18^{*}$ & \\
\hline
\end{tabular}

The correlations between $\mathrm{T} 1$ and $\mathrm{T} 2$ are correlations between latent variables. The correlations from $\mathrm{T} 2$ and above are correlations between the disturbance terms

$* p<.05 ; * * p<.01 ; * * * p<.001$

that the constrained model did not significantly differ from the unconstrained model $\left[\Delta \chi^{2}(16)=12.852, p>.05\right]$, implying that associations between sibling warmth and parental support did not differ between same-sex and mixed-sex dyads. In regard to sibling conflict and parental support, we also found no significant differences between same-sex and mixed-sex dyads $\left[\Delta \chi^{2}(16)=21.996\right.$ $p>$.05].

\section{Model Findings for First-Born Siblings}

We also tested the cross-lagged model (see Fig. 1) in the sample of first-born siblings. The model of sibling warmth and adolescents' reports of parental support showed a satisfactory fit to the data $\left[\chi^{2}(141, N=428)=422.289\right.$, $p=.000, \mathrm{CFI}=.959$, and RMSEA $=.068]$. However, we did not find any significant association between sibling warmth and parental support at any of the five waves (see Table 3). Although the model of sibling conflict and adolescents' reports of parental support also showed a satisfactory fit to the data $\left[\chi^{2}(141, N=428)=387.652\right.$, $p=.000, \mathrm{CFI}=.954$, and $\mathrm{RMSEA}=.064]$, we again found no significant associations between sibling conflict and parental support (see Table 4). Thus, for first-born siblings, no associations occurred between sibling warmth and conflict on one hand and their reports of parental support on the other.
Model Findings for Parents' Reports of Parental Support

In addition to the cross-lagged models for adolescents' reports of parental support and the quality of the sibling relationship, we tested the cross-lagged model (see Fig. 1) for parents' reports of parental support. Because the Pearson correlations between maternal and paternal support were low $(.21>r<.28)$, we ran the models separately for maternal and paternal support. The model for maternal support and sibling warmth as well as sibling conflict showed a satisfactory fit to the data [respectively: $\chi^{2}(141, N=428)=422.973, p=.000, \mathrm{CFI}=.955$, and RMSEA $=.068$ and $\chi^{2}(141, N=428)=368.040, p=$ $.000, \mathrm{CFI}=.957$, and $\mathrm{RMSEA}=.061]$. The parcels accurately assessed the latent variables of maternal support in both models, with factor loadings ranging from .79 to 92. Maternal support was also stable over time, with betas ranging from .75 to .85 . In contrast to the models based on adolescents' reports, we found no significant associations between mothers' reports of maternal support and sibling warmth or conflict.

Furthermore, the models for paternal support and sibling relationships also showed a satisfactory fit to the data $\left[\chi^{2}(141, N=428)=377.318, p=.000, \mathrm{CFI}=.963\right.$, and RMSEA $=.063$ for warmth and $\chi^{2}(141, N=428)=$ $327.898, p=.000, \mathrm{CFI}=.965$, and RMSEA $=.056$ for conflict]. In both models, the latent variable paternal support was stable over time (with betas ranging from .84 to .94) and was accurately assessed by the parcels (factor loadings ranging from .74 to .90). However, we found four significant associations that did not show a consistent pattern: sibling warmth at T1 was positively associated with paternal support at T2 $(\beta=.09, p=.012)$; paternal support at T4 was negatively associated with sibling warmth at $\mathrm{T} 5(\beta=-.10, p=.037)$; paternal support at $\mathrm{T} 1$ was negatively associated with sibling conflict at T2 $(\beta=-.15, p=.004)$; and sibling conflict at T3 was negatively associated with paternal support at $\mathrm{T} 4 \quad(\beta=$ $-.09, p=.036)$.

\section{Discussion}

Sibling relationships and parental support are important for adolescents' development and well-being. Research shows that both are likely to change during adolescence but little is known about the longitudinal and bidirectional associations between sibling relationships and parental support. In this study, we, therefore, tested the longitudinal and bidirectional associations of parental support with sibling warmth and conflict during adolescence. Our results partially confirmed the congruence hypothesis by demonstrating 
prospective associations between both sibling warmth and conflict and adolescents' reports of parental support in early adolescence. In other words, young adolescents with warmer and less conflictual sibling relationships perceive more parental support the subsequent year. Sibling relationships characterized by high levels of conflict may cause parents to interfere in the relationship in an attempt to diminish the conflicts. In doing so, they are likely to disagree with or reprimand one or both siblings; consequently, siblings may perceive these parental behaviors as an indication of less support.

In contrast to our expectations, we did not find a prospective association between adolescents' reports of parental support and the quality of sibling relationships over time. Thus, our results suggest a spillover from sibling warmth and conflict to parental support, but not the other way around. Moreover, the prospective associations between sibling relationships and adolescent-reported parental support were found only in early adolescence, not later on. Most previous studies that investigated links between parent-child relationships and sibling relationships were either cross-sectional or investigated the associations in childhood (Brody et al. 1994b; McGuire et al. 1996; Rinaldi and Howe 2003; Seginer 1998), which might explain why our results differ from previous studies. In accordance with social learning theory and attachment theory, the congruence hypothesis states that children learn how to behave in relationships by modeling or through their internal working models based on their relationships with their parents (Brody et al. 1994b; Stocker 2000). Since younger children perceive their parents as important role models, a spillover from the parent-child relationship to the sibling relationship-rather than the other way around - could be more prominent in childhood. However, in early adolescence, peers increase in importance (e.g., Furman and Buhrmester 1992; Scholte et al. 2001); thus, older siblings - rather than parents - may function as role models. This would suggest that a spillover from sibling relationships to parent-child relationships, rather than vice versa, could be expected. Later in adolescence, adolescents will focus more on friends than on family members, resulting in more autonomous sibling relationships that consequently relate less to parental support (Scharf et al. 2005).

Kim et al. (2006) longitudinally investigated the links between parent-child relationships and sibling relationships during adolescence, finding that parent-child relationships covaried with sibling relationships during adolescence. However, because of their study design, these authors did not examine bidirectional associations. Based on our results, we would argue that a spillover from sibling relationships to parental support is more prominent in early adolescence. Our results from first-born siblings seem to confirm this assumption as they show no associations between sibling relationship quality and parental support. In other words, these results indicate that a spillover between sibling relationships and parental support disappears as adolescents grow older. It might be important to consider adolescents' home leaving in this matter, because for them family relationships may become less central when they have left home. Therefore, it would be interesting for future research to examine the effects of adolescents' home leaving on associations among family relationships.

Although changes in sibling relationships during adolescence seem to differ based on the gender constellation of the sibling dyad (Buhrmester and Furman 1990; Cicirelli 1995; Cole and Kerns 2001; Kim et al. 2006), we found no difference for same-sex versus mixed-sex dyads in the associations between sibling relationships and parental support. As such, it might be that only the development of the sibling relationship during adolescence differs for same-sex versus mixed-sex dyads and that the prospective associations between sibling relationships and parental support are the same for same-sex and mixed-sex dyads. However, we were not able to investigate the bidirectional associations for all four gender constellation dyads (i.e., boy-boy, girl-girl, boy-girl, and girl-boy). Since sibling relationships differ depending on the gender of the adolescent and that of his or her sibling (e.g., Cole and Kerns 2001), future research is warranted to examine whether the same pattern of findings applies for male adolescents who have a sister versus a brother as well as female adolescents who have a sister versus a brother.

As previously discussed, our understanding of the associations between sibling relationships and parental support may be incomplete if we rely exclusively on adolescents' self-reports (e.g., Bogenschneider and Pallock 2008). Thus, we also investigated whether paternal and maternal support as reported by parents was associated with sibling relationships. Our descriptive data suggest that adolescents and parents have different perceptions of parental support, since the mean levels of adolescentreported and parent-reported parental support differed significantly at all five waves and correlations between adolescents' reports of parental support and parents' reports of parental support were low. Moreover, in contrast to our findings that sibling relationships are associated with adolescent-reported parental support, we found no consistent associations between sibling relationships and parentreported maternal or paternal support. Since adolescents are part of both the sibling relationship and the parentchild relationship, adolescents' subjective experience of parental support might be more significant than parents' reports of support. However, we have to be careful in our conclusions when comparing the models of adolescents' 
reports and parents' reports of support because we combined adolescents' reports of maternal and paternal support into a latent variable, whereas parents' report on maternal and paternal support were explored separately.

\section{Conclusions, Limitations, and Implications}

The present study extends previous research by examining bidirectional associations between parental support and sibling relationships for five consecutive years during adolescence. We found a spillover from sibling relationships to adolescent-reported parental support in early adolescence, but not the other way around. Such associations were found for sibling warmth as well as sibling conflict, suggesting that associations between sibling relationships and adolescent-reported parental support in early adolescence are robust. Consequently, our results are in line with the congruence (spillover) hypothesis. This study also points out the importance of not only longitudinally investigating associations between family relationships but also using a design that investigates bidirectional associations. A spillover from the parent-child relationship to the sibling relationship may be more common in childhood, but the spillover seems to reverse in early adolescence and disappear later on.

There are some limitations that should be kept in mind. First, it is important to note that our study does not exclude the possibility of compensation in some situations, as disharmonious families were not included in our study. Thus, we should be cautious when generalizing the present findings to, for example, non-intact families. Furthermore, it is unclear to what extent our findings hold for families in non-Western cultures. Future research might want to investigate the bidirectional associations between sibling relationships and parental support in disharmonious families and families in other cultures. Second, we were not able to investigate the associations between sibling relationships and parental support in all four different gender constellation dyads (i.e., boy-boy, girl-girl, boy-girl, and girl-boy). Given that parent-child and sibling relationships can have different meaning depending on the gender constellation of the sibling pair (e.g., Scholte et al. 2007), it awaits further study to examine whether our findings differ according to gender constellation. Third, although parental support is an important characteristic of the parent-child relationship (Levitt et al. 2007), other characteristics, such as parent-child conflict, might be differently associated with the sibling relationship. It would be interesting to further examine associations between parent-child characteristics and sibling relationships.

Our results provide insights for therapists who provide professional help to young adolescents and their families. Since the quality of sibling relationships is associated with adolescents' perceptions of parental support 1 year later, therapists should not focus solely on parent-child relationships, but should also consider including assessing the sibling relationships in therapies. Moreover, it is important to understand that-if sibling relationship quality drops in early adolescence-adolescents may perceive their parents as being less supportive, although parents might not be aware of this themselves. For adolescents, this means that both sibling relationship quality and parental support decline, which might have negative consequences for adolescents' well-being and development. Future research should investigate this in more detail.

Open Access This article is distributed under the terms of the Creative Commons Attribution Noncommercial License which permits any noncommercial use, distribution, and reproduction in any medium, provided the original author(s) and source are credited.

\section{References}

Baltes, M. M., \& Silverberg, S. B. (1994). The dynamics between dependency and autonomy: Illustrations across the life span. In D. L. Featherman, P. B. Baltes, R. M. Lerner, \& M. Perlmutter (Eds.), Life-span development and behavior, vol. 12 (pp. 41-90). Hillsdale, NJ: Erlbaum.

Bandalos, D. L., \& Finney, S. J. (2001). Item parceling issues in structural equation modeling. In G. A. Marcoulides \& R. E. Schumacker (Eds.), Advanced structural equations modeling: New developments and techniques (pp. 269-296). Mahwah, NJ: Lawrence Erlbaum Associates.

Blyth, D. A., Hill, J. P., \& Smith Thiel, K. (1982). Early adolescents' significant others: Grade and gender differences in perceived relationships with familial and nonfamilial adults and young people. Journal of Youth and Adolescence, 11, 425-450.

Bogenschneider, K., \& Pallock, L. (2008). Responsiveness in parentadolescent relationships: Are influences conditional? Does the reporter matter? Journal of Marriage and Family, 70, 1015-1029.

Brody, G. H., Stoneman, Z., \& McCoy, J. K. (1994a). Forecasting sibling relationships in early adolescence from child temperaments and family processes in middle childhood. Child Development, 65, 771-784.

Brody, G. H., Stoneman, Z., \& McCoy, J. K. (1994b). Contributions of family relationships and child temperaments to longitudinal variations in sibling relationship quality and sibling relationship styles. Journal of Family Psychology, 8, 274-286.

Buhrmester, D., \& Furman, W. (1990). Perceptions of sibling relationships during middle childhood and adolescence. Child Development, 61, 1387-1398.

Cicirelli, V. G. (1995). Sibling relationships across the life span. New York, USA: Plenum Press.

Cole, A., \& Kerns, K. A. (2001). Perceptions of sibling qualities and activities of early adolescents. Journal of Early Adolescence, 21, 204-227.

Crane, D. R., Allgood, S. M., Larson, J. H., \& Griffin, W. (1990). Assessing marital quality with distressed and nondistressed couples: A comparison and equivalency table for three frequently used measures. Journal of Marriage and the Family, 52, 87-93.

De Goede, I. H. A., Branje, S. J. T., \& Meeus, W. H. J. (2009). Developmental changes in adolescents' perceptions of 
relationships with their parents. Journal of Youth and Adolescence, 38, 75-88.

De Leeuw, R. N. H., Engels, R. C. M. E., Vermulst, A. A., \& Scholte, R. H. J. (2008). Do smoking attitudes predict behaviour? A longitudinal study on the bi-directional relations between adolescents' smoking attitudes and behaviours. Addiction, 103, $1713-1721$.

Derkman, M. M. S., Scholte, R. H. J., Van Der Veld, W. M., \& Engels, R.C. M. E. (2010). Factorial and construct validity of the Sibling Relationship Questionnaire. European Journal of Psychological Assessment, 26.

Furman, W., \& Buhrmester, D. (1985). Children's perceptions of the qualities of sibling relationships. Child Development, 56, $448-461$.

Furman, W., \& Buhrmester, D. (1992). Age and sex differences in perceptions of networks of personal relationships. Child Development, 63, 103-115.

Garnefski, N., \& Diekstra, R. F. W. (1996). Perceived social support from family, school, and peers: Relationship with emotional and behavioral problems among adolescents. Journal of the American Academy of Child \& Adolescent Psychiatry, 35, 1657-1664.

Ha, T., Overbeek, G., Vermulst, A. A., \& Engels, R. C. M. E. (2009). Marital quality, parenting, and adolescent internalizing problems: A three-wave longitudinal study. Journal of Family Psychology, 23, 263-267.

Harakeh, Z., Scholte, H. J., De Vries, H., \& Engels, R. C. M. E. (2005). Parental rules and communication: Their association with adolescent smoking. Addiction, 100, 862-870.

Helsen, M., Vollebergh, W., \& Meeus, W. (2000). Social support from parents and friends and emotional problems in adolescence. Journal of Youth and Adolescence, 29, 319-335.

Hu, L., \& Bentler, P. M. (1999). Cutoff criteria for fit indices in covariance structure analysis: Conventional criteria versus new alternatives. Structural Equation Modeling, 6, 1-55.

Jenkins, J. (1992). Sibling relationships in disharmonious homes: Potential difficulties and protective effects. In F. Boer \& J. Dunn (Eds.), Children's sibling relationships: Developmental and clinical issues (p. 125-138). Hillsdale, NJ: Lawrence Erlbaum Associates.

Kim, J., McHale, S. M., Crouter, A. C., \& Osgood, W. (2007). Longitudinal linkages between sibling relationships and adjustment from middle childhood through adolescence. Developmental Psychology, 43, 960-973.

Kim, J., McHale, S. M., Osgood, D. W., \& Crouter, A. C. (2006). Longitudinal course and family correlates of sibling relationships from childhood through adolescence. Child Development, 77, 1746-1761.

Levitt, M. J., Guacci-Franco, N., \& Levitt, J. L. (1993). Convoys of social support in childhood and early adolescence: Structure and function. Developmental Psychology, 29, 811-818.

Levitt, M. J., Silver, M. E., \& Santos, J. D. (2007). Adolescents in transition to adulthood: Parental support, relationship satisfaction, and post-transition adjustment. Journal of Adult Development, 14, 53-63.

Locke, H. J., \& Wallace, K. M. (1959). Short marital-adjustment and prediction tests: Their reliability and validity. Marriage and Family Living, 21, 251-255.

McGuire, S., McHale, S. M., \& Updegraff, K. (1996). Children's perceptions of the sibling relationship in middle childhood: Connections within and between family relationship. Personal Relationships, 3, 229-239.

McHale, S. M., Kim, J., \& Whiteman, S. D. (2006). Sibling relationships in childhood and adolescence. In P. Noller \& J. A. Feeney (Eds.), Close relationships: Functions, forms and processes (pp. 127-149). Hove, England: Psychology Press/ Taylor \& Francis.
Meeus, W., Iedema, J., Maassen, G., \& Engels, R. (2005). Separationindividuation revisited: On the interplay of parent-adolescent relations, identity, and emotional adjustment in adolescence. Journal of Adolescence, 28, 89-106.

Muthén, L. K. \& Muthén, B.O. (1998-2007). Mplus user's guide, 5th edn. Los Angeles, CA: Muthén \& Muthén.

Nasser, F., \& Takahashi, T. (2003). The effect of using item parcels on ad hoc goodness- of-fit indexes in confirmatory factor analysis: An example using Sarason's Reactions to Tests. Applied Measurement in Education, 16, 75-97.

Noller, P. (2005). Sibling relationships in adolescence: Learning and growing together. Personal Relationships, 12, 1-22.

Raffaelli, M. (1992). Sibling conflict in early adolescence. Journal of Marriage and the Family, 54, 652-663.

Rinaldi, C. M., \& Howe, N. (2003). Perceptions of constructive and destructive conflict within and across family subsystems. Infant and Child Development, 12, 441-459.

Sarason, I. G., Pierce, G. R., \& Sarason, B. R. (1990). Social support and interactional processes: A triadic hypothesis. Journal of Social and Personal Relationships, 7, 495-506.

Scharf, M., Shulman, S., \& Avigad-Spitz, L. (2005). Sibling relationship in emerging adulthood and in adolescence. Journal of Adolescent Research, 20, 64-90.

Scholte, R. H. J., Engels, R. C. M. E., de Kemp, R. A. T., Harakeh, Z., \& Overbeek, G. (2007). Perceived parental differential treatment, sibling relationships, and delinquency in adolescence. Journal of Youth and Adolescence, 36, 661-671.

Scholte, R. H. J., Van Lieshout, C. F. M., \& Van Aken, M. A. G. (2001). Perceived relational support in adolescence: Dimensions, configurations, and adolescent adjustment. Journal of Research on Adolescence, 11, 71-94.

Seginer, R. (1998). Adolescents' perceptions of relationships with older siblings in the context of other close relationships. Journal of Research on Adolescence, 9, 287-308.

Stocker, C. M. (2000). Sibling relationships. In A. E. Kazdin (Ed.), Encyclopedia of psychology, 7 (pp. 274-279). Washington, D.C./ New York, USA: American Psychological Association/xford University Press.

Van Der Vorst, H., Engels, R. C. M. E., Meeus, W., Deković, M., \& Van Leeuwe, J. (2005). The role of alcohol-specific socialization in adolescents' drinking behavior. Addiction, 100, 1464-1476.

Voorpostel, M., \& Blieszner, R. (2008). Intergenerational solidarity and support between adult siblings. Journal of Marriage and Family, 70, 157-167.

Whitchurch, G. G., \& Constantine, L. L. (1993). Systems theory. In P. G. Boss, W. J. Doherty, R. LaRossa, W. R. Schumm, \& S. K. Steinmetz (Eds.), Sourcebook of family theories and methods: A contextual approach (pp. 325-355). New York, USA: Plenum.

Yeh, H., \& Lempers, J. D. (2004). Perceived sibling relationship and adolescent development. Journal of Youth and Adolescence, 33, 133-147.

\section{Author Biographies}

Marleen M. S. Derkman is a Ph.D. student at the Behavioural Science Institute of the Radboud University of Nijmegen, The Netherlands. Her main research interest includes sibling relationships during adolescence.

Rutger C. M. E. Engels is a Professor at the Behavioural Science Institute of the Radboud University of Nijmegen, The Netherlands. $\mathrm{He}$ received his Ph.D. at Maastricht University. His main research interests concern adolescents' health risk behaviours. 
Emmanuel Kuntsche works at a Research Department of the Swiss Institute for the Prevention of Alcohol and Drug Problems in Lausanne, Switzerland. His main research interests concern adolescents' alcohol use and behaviour.

Haske van der Vorst is an Assistant Professor at the Behavioural Science Institute of the Radboud University Nijmegen. She received her Ph.D. at Radboud University of Nijmegen, The Netherlands. Her main research interests concern adolescents' alcohol use and alcohol cognitions of children.
Ron H. J. Scholte is an Associate Professor at the Behavioural Science Institute of the Radboud University of Nijmegen, The Netherlands. His main research interests are adolescents' and young adults' social development. 